\title{
Correction to: Yttrium-90 Radioembolization for BCLC Stage C Hepatocellular Carcinoma Comparing Child-Pugh A Versus B7 Patients: Are the Outcomes Equivalent?
}

\author{
Qingquan $\mathrm{Zu}^{1,2} \cdot$ Ryan C. Schenning $^{1}$ - Younes Jahangiri ${ }^{1} \cdot$ Yuki Tomozawa $^{1}$ \\ Kenneth J. Kolbeck ${ }^{1} \cdot$ John A. Kaufman ${ }^{1} \cdot$ Ramsey Al-Hakim $^{1} \cdot$ Willscott E. Naugler ${ }^{3}$. \\ Nima Nabavizadeh ${ }^{4} \cdot$ Adel Kardosh $^{5} \cdot$ Kevin G. Billingsley $^{6} \cdot$ Skye C. Mayo $^{6}$. \\ Susan L. Orloff ${ }^{6} \cdot$ C. Kristian Enestvedt ${ }^{6} \cdot$ Erin Maynard $^{6} \cdot$ Joseph Ahn $^{3}$. \\ Dekey Lhewa ${ }^{3} \cdot$ Khashayar Farsad $^{1}($ (i) \\ Published online: 16 June 2020 \\ (C) Springer Science+Business Media, LLC, part of Springer Nature and the Cardiovascular and Interventional Radiological Society of Europe \\ (CIRSE) 2020
}

\section{Correction to:}

Cardiovasc Intervent Radiol (2020) 43:721-731 https://doi.org/10.1007/s00270-020-02434-4

The name of one of the co-authors was slightly misspelled. Kristian Enestvedt is listed currently as "Kristian K. Enestvedt" and should be listed instead as "C. Kristian Enestvedt."

The original article can be found online at https://doi.org/10.1007/ s00270-020-02434-4.

Khashayar Farsad

farsad@ohsu.edu

Qingquan $\mathrm{Zu}$

zuqingquan@njmu.edu.cn

Ryan C. Schenning

schennin@ohsu.edu

Younes Jahangiri

jahangiy@ohsu.edu

Yuki Tomozawa

tomozawa@belle.shiga-med.ac.jp

Kenneth J. Kolbeck

kolbeckk@ohsu.edu

John A. Kaufman

kaufmajo@ohsu.edu
Publisher's Note Springer Nature remains neutral with regard to jurisdictional claims in published maps and institutional affiliations.
Ramsey Al-Hakim alhakim@ohsu.edu

Willscott E. Naugler nauglers@ohsu.edu

Nima Nabavizadeh nabaviza@ohsu.edu

Adel Kardosh kardosh@ohsu.edu

Kevin G. Billingsley kevin.billingsley@yale.edu

Skye C. Mayo mayos@ohsu.edu

Susan L. Orloff orloffs@ohsu.edu 
C. Kristian Enestvedt

enestved@ohsu.edu

Erin Maynard

maynarde@ohsu.edu

Joseph Ahn

ahnj@ohsu.edu

Dekey Lhewa

lhewad@ohsu.edu

1 Dotter Department of Interventional Radiology, Oregon Health and Science University, 3181 SW Sam Jackson Park Road, L-605, Portland, OR 97239, USA

2 Department of Interventional Radiology, The First Affiliated Hospital with Nanjing Medical University (Jiangsu Province Hospital), Nanjing, China
3 Division of Gastroenterology and Hepatology, Oregon Health and Science University, 3181 SW Sam Jackson Park Road, L-605, Portland, OR 97239, USA

4 Radiation Oncology, Oregon Health and Science University, 3181 SW Sam Jackson Park Road, L-605, Portland, OR 97239, USA

5 Medical Oncology, Oregon Health and Science University, 3181 SW Sam Jackson Park Road, L-605, Portland, OR 97239, USA

6 Surgery, Oregon Health and Science University, 3181 SW Sam Jackson Park Road, L-605, Portland, OR 97239, USA 